\title{
High temperature fiber sensor based on a thermo-mechanical written LPG
}

\author{
J.M. Lazaro*, A. Quintela, P.B. Garcia-Allende, J. Mirapeix, C. Galindez and J.M. Lopez-Higuera \\ Photonic Engineering Group (Dpto. TEISA), University of Cantabria, Avda. Los Castros s/n, Plaza \\ de la Ciencia, Edificio de I+D de Telecomunicación, 39005 - Santander; \\ *jmlu@teisa.unican.es; phone +32 942 200877- Ext.12; fax +34 942 200877; http://www.teisa.unican.es/gif
}

\begin{abstract}
An optical fibre transducer able to work in high temperatures environments is experimentally demonstrated in the laboratory. It is based on a permanent Long period gratings (PLPG) written using a thermo-mechanical technique. The fabrication technique, the experimental works, their results and the conclusions are presented and discussed in this paper.
\end{abstract}

Keywords: long period gratings, mechanical technique, fabrication, permanent LPG, high temperature sensor.

\section{INTRODUCTION}

Optical fiber sensors advantages with respect conventional ones (small size, interferences immunity, possibility of long distance interrogation, etc.) enable their use in a wide set of application fields (chemistry, civil engineering, biomedicine, etc) [1]. A lot of techniques are used in these sensors (interferometry, spectrometry, gratings, etc) and it is worth mentioning that an important percent, are based on optical fiber grating structures. In addition, these devices are able to realise wavelength multiplexing and hence quasi-distributed sensor networks can be build.

A wide number of techniques can be used to produce the located refractive index change in the fiber (principally in the core). In some cases it is obtained by local densifications of the fiber materials (using infrared radiations, electric arc, $\mathrm{CO}_{2}$ laser, dopants diffusion, mechanical deformations,....) [2-6] and, in others, using the popular UV photosensitivity $[7,9]$.

Fibre gratings with long period with respect the wavelength or, long period grating (LPG), can be used to measure temperature. However, when grating structures are placed on high temperature environments, they can suffer a degradation on their optical behaviours (as happen with the ones written using UV photosensitivity technique) and, hence they employment for this purpose is drastically reduced.

To avoid the mentioned trouble, in this paper an un-expensive thermo-mechanical technique is proposed to fabricate permanent LPG structures and able to work in high temperatures. The fabrication and characterization set-ups, the results discussion and the conclusions of LPG's written with the proposed technique are presented in this paper.

\section{EXPERIMENTAL SETUP}

The proposed technique consists on locate a periodically grooved plate over a region of the fiber and them expose the fiber to high temperature using a very localized flame. The result is the writing of the grooves shape over the fiber. In order to probe this technique the setup showed in Fig. 1 has been developed. The part of the fiber in which the grooved plate is located is placed on a linear translator controlled by computer. A hydrogen flame $\left(\sim 2000^{\circ} \mathrm{C}\right)$ is located in a fix position transverse to the fiber. On this way, several sweeps with the flame can be made along the region where the grooves are over the fiber. This allows writing the periodic structure of the grooves in the fiber and thus a permanent LPG is obtained. During the fabrication the LPG, the optical behaviours are monitorized using a broadband light source (Agilent 83437A) and an optical spectrum analyzer (HP86142A). The source consist of 4 LEDs covering the spectral range of 1200 to $1700 \mathrm{~nm}$ which is enough for this experiment.

20th International Conference on Optical Fibre Sensors, edited by Julian Jones, Brian Culshaw, Wolfgang Ecke, José Miguel López-Higuera, Reinhardt Willsch, Proc. of SPIE Vol. 7503, 75033W (c) 2009 SPIE - CCC code: $0277-786 X / 09 / \$ 18 \cdot$ doi: 10.1117/12.835301 


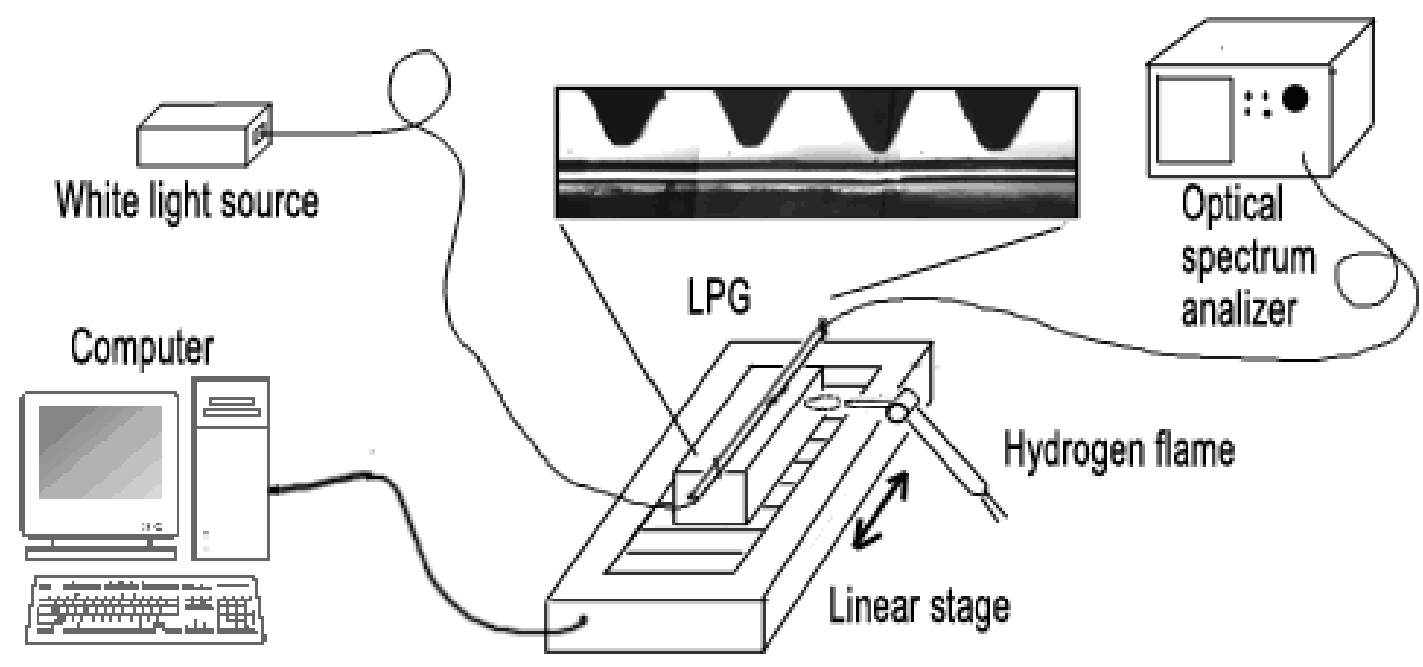

Fig. 1.Experimental setup

\section{RESULTS}

A grooved plate of period $0.7 \mathrm{~mm}$ was located over the fiber and after several sweeps with the flame, a LPG was written with the proposed technique. On figure 2 the spectral response of the LPG obtained is shown.

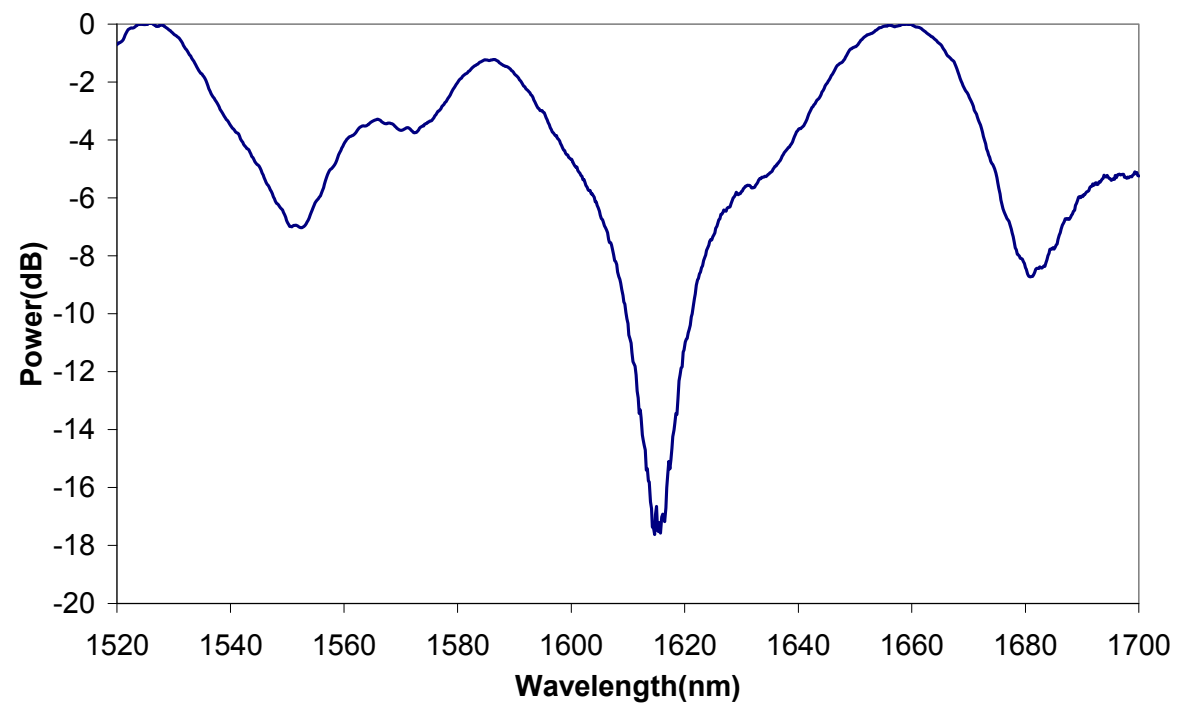

Fig. 2. Spectral response of the thermo-mechanical LPG

To demonstrate the feasibility of use these LPG's on high temperature the LPG was checked using a furnace (Carbolite MTF 12/38/250). The LPG in fiber with a very small weight (to maintain it in vertical position) was introduced inside the tube-furnace placed in upright position. Maintaining the LPG straight the shift of the peak with curvatures is avoided. A thermocouple was used to measure the temperature in the furnace.

A temperature sweep was carried out between 20 to $532{ }^{\circ} \mathrm{C}$, which is the maximum that can be obtained with the furnace in this position. The evolution of the first resonance (maximum attenuation peak) with the temperature is summarized in figure 3. A peak shift of $10 \mathrm{~nm}$ in the mentioned temperature change is obtained. To check if this LPG presents 
hysteresis, several cycles up and down (increasing and decreasing) of the temperatures were realized and no hysteresis effect was observed. The peak returns to the original position.

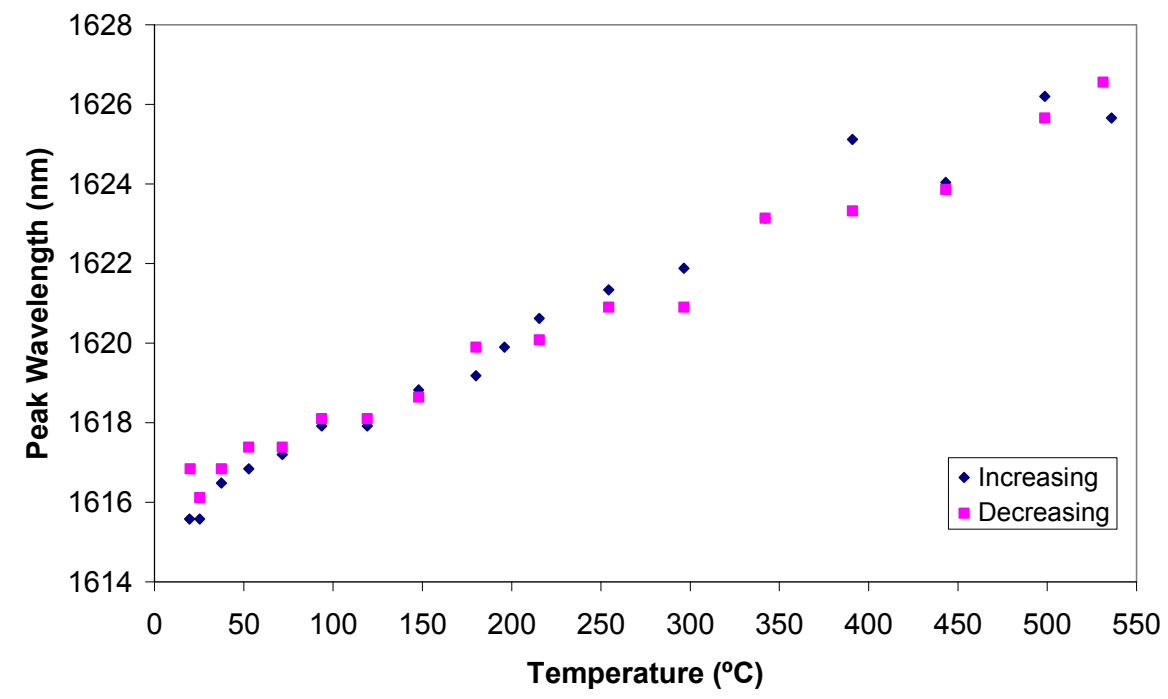

Fig. 3. Evolution of the peak wavelength with the temperature. Increasing (blue) and decreasing (pink) the temperature.

Finally, the stability of the LPG in high temperature was also characterized. The grating was subject to $532{ }^{\circ} \mathrm{C}$ during 17 hours. It was observed that the LPG remains with the same attenuation peak after this time. The wavelength of the peaks is also very stable. Fig. 4 shows the spectrum before and after 17 hours at $532{ }^{\circ} \mathrm{C}$.

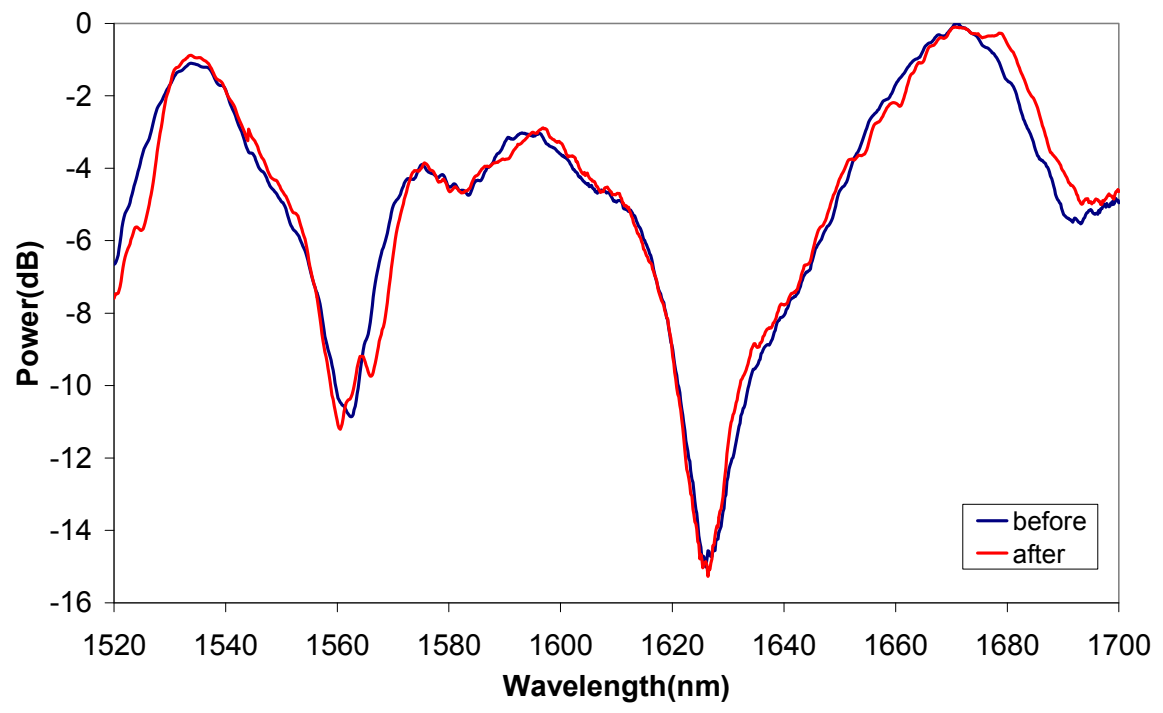

Fig. 4: Spectral response of the thermo-mechanical LPG at $532^{\circ} \mathrm{C}$ before (blue) and after 17 hours (red)

\section{CONCLUSIONS}

A permanent LPG written using a modification of the mechanical technique has been demonstrated. In this technique a hydrogen flame is applied to a fiber with a periodical grooved plate and thus the structure is modified periodically. The LPG behaviour is checked working inside a high temperature range following a series of cycles. The calibration curve is obtained and no hysteresis was observed. Very good stability of the attenuation peak is observed maintaining the LPG a 
$532{ }^{\circ} \mathrm{C}$ during a period of time. The results demonstrate that this technique allow the fabrication of permanent LPGs useful for applications like filters and sensors to work inside high temperature ranges.

\section{ACKNOWLEDGMENTS}

This work was supported in part by the Spanish Government TEC2007-67987-C02-01 project.

\section{REFERENCES}

[1] J.M. López-Higuera, "Handbook of Optical Fiber Sensing Technology”, Wiley (2002).

[2] M Fujumaki, Y Ohki, J L Brebner and S Roorda, "Fabrication of long-period optical fibre gratings by use of ion implantation", Optics Letters, v25, 88-90, (2000)

[3] Y Kondo, K Nouchi, T Mitsuyu, M Watanabe, P Kazansky, K Hirao "Fabrication of long-period fibre gratings by focused irradiation of infra-red femtosecond laser pulses", Optics Letters, v24, , 646-8,1999.

[4] D D Davis, T K Gaylord, E N Glytsis, S G Kosinski, S C Mettler, A M Vengsarkar, "Long-period fibre grating fabrication with focused CO2 laser beams" Electronics Letters, v34 302-3,1998

[5] G Rego, O Okhotnikov, E Dianov, V Sulimov, "High-temperature stability of long-period fibre gratings using an electric arc", Journal Lightwave Technology, v19, 1574-9, 2001

[6] S Savin, M J F Digonnet, G S Kino, H J Shaw, "Tunable mechanically induced long-period fibre gratings", Optics Letters, v25 710-12, 2000

[7] V Bhatia, A M Vengsarkar, "Optical fibre long-period grating sensors", Optics Letters, v21, 692-4, 1996

[8] B-Ou Guan, H-Y Tam, S-L Ho, S-Y Liu, Dong X-Y "Growth of long-period gratings in H2-loaded fibre after 193 nm UV inscription", IEEE Photonics Technology Letters, v12, 642-4, 2000

[9] J Blows and D Y Tang "Gratings written with tripled output of Q-switched Nd:YAG laser", Electronics Letters, v36, $1837-9,2000$ 